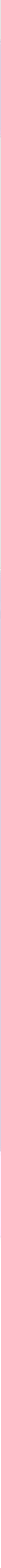




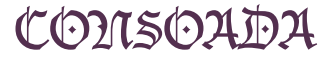

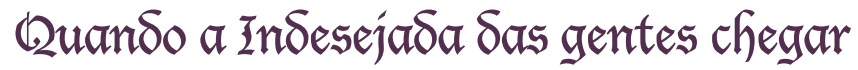
(2rão sei se Sura ou caroádel), Tafbez eu tenfa meso.

Calvez sorria, ou Siga: - Alô, inifúínel!

AGUINALDO JOSÉ GONÇALVES

$\odot$ meu Sia foí bom, pose a noite Sescer.

(24 noite com os seus sortílégíos.)

Encontrarálabradoo campo, acasalimpa,

2 mesa posta,

Com casa coisa em seu fugar.

(21anuel23andeíra).

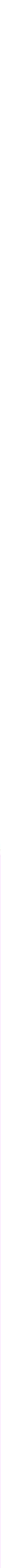




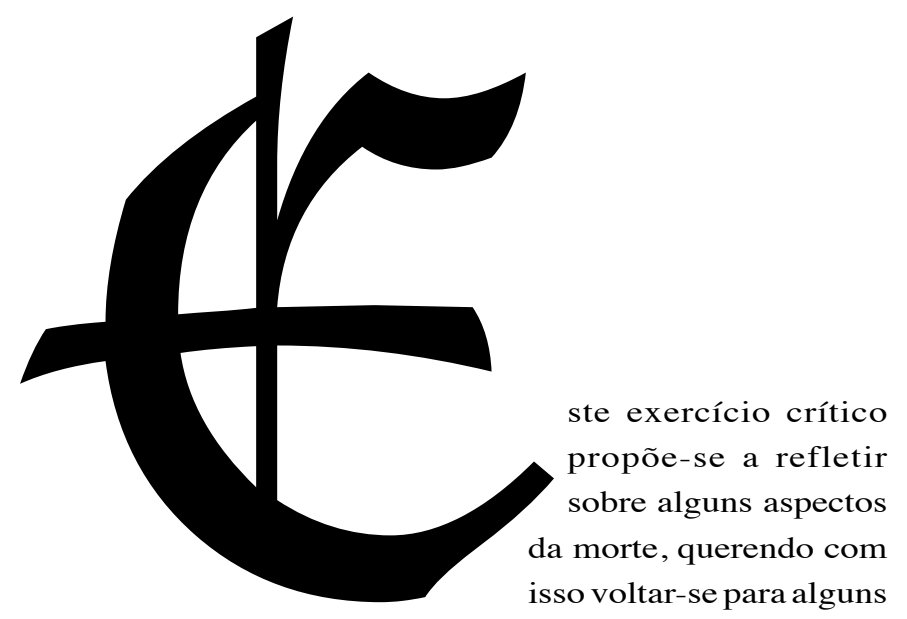

filamentos da vida, em sua magnitude e em sua pequenez. Vivendo e vivenciando e olhando e se assustando a cada dia com o que se vive, com o que se morre, com o que se negaceia no ato de viver e de dizer que se vive, com os discursos sobre a morte e com os desesperos diante da vida, tornou-se impossível a mim não pensar sobre tudo isso e começar a "ensaiar" uma reflexão sobre viver e morrer. Portanto, ao denominar este texto de "A Sétima Instância da Morte", entendi que poderia ser lido no seu avesso: "A Primeira Instância da Vida”. Para aquecer discussão tão tênue e ao mesmo tempo tão ácida, a obra de arte será convocada para nos auxiliar. Afora a epígrafe do texto, duas obras serão focalizadas ao longo da reflexão e outras serão convidadas no devido momento: a novela A Morte de Ivan Ilitch, de Leon Tolstói (1886), e o filme O Sétimo Selo, de Ingmar Bergman (1957). Pertencerem a sistemas semióticos distintos causa maior relevo uma vez que esse procedimento de homologias acaba criando o que se denomina a "mútua iluminação das artes" para a compreensão de tema tão complexo.
Há muitos anos, havia lido a novela de Tolstói. Restavam em meu espírito riscos temáticos de uma morte realista. Relendo Metamorfose, de Kafka, decidi também reler A Morte de Ivan Ilitch, um pouco ensimesmado, confesso. A aparente linearidade que determinava seus cinco primeiros capítulos dava-me uma impressão de constatação realista, no seu sentido estrito de objetividade referencial. Entretanto, a motivação composicional do texto era outra. Conduzia-me com maior visibilidade para as realizações cinematográficas. Por falta dessa linguagem no seu tempo, parece que o escritor russo a intuiu e valeu-se de técnicas muito próximas daquilo que só a linguagem fílmica pode realizar. O tema da novela se explicita desde o início: a morte e seus sortilégios. Um deles, o terrível medo da aproximação da morte e, paradoxalmente, o aprendizado pelo sofrimento. A notícia da morte da personagem Ivan Ilitch eclode logo no início da novela. Emerge no seio da repartição pública onde trabalhava na Rússia do final do século XIX. Também se apresentam os efeitos dessa morte na mente e nas falas dos colegas. Torna-se menos relevante a morte de Ivan e bem mais a morte de seu cargo, que implicará mudanças nos cargos dos demais funcionários. Portanto, não se trata da questão da morte como fato consumado, mas das tensões de vida que surgem à volta da morte. Portanto, trata-se de uma questão de vida. A partir do momento em que se tem a notícia de morte, iniciam-se os jogos da preterição e da ironia em que o verdadeiro e o falso se mesclam. As perguntas sobre o morto, sobre as circunstâncias da morte são de falsa retórica e evasivas. A obrigatoriedade de visita ao velório torna-se um fardo, mesmo para aqueles mais próximos do falecido. A morte se apresenta com essa "pálida fisionomia", como tão bem é figurativizada no filme de Bergman: a pálida imagem vestida de preto. Faz da condição humana essa máscara da ignomínia e quase de desesperança. Não entendermos a morte no seu mistério e ao mesmo tempo nos atrair pelo seu fascínio. Não justifica fazermos dela o pretexto para revelar nossa cegueira e o mais baixo estado de nossa condição. Isso 
é aterrador. As perguntas, nessas circunstâncias e em especial na novela em questão, são evasivas e, por isso, reveladoras. Doze capítulos criam um moto-perpétuo na caminhada de um indivíduo para a morte. É uma narrativa realista que se vale do brilho de um estilo para aproximar a câmara da vida como ela é.

Já nas primeiras linhas, a notícia da morte de Ivan Ilitch vem à repartição onde o protagonista trabalhava, por meio do jornal que, por acaso, era lido por Piotre Ivanovitch, que não intervinha na palestra dos demais colegas e o folheava. O jornal "cheirava a tinta fresca", diz o narrador. $\mathrm{O}$ morto era colega daqueles senhores e todos o apreciavam muito. A notícia tomou conta dos pensamentos de vários colegas que poderiam ocupar o lugar de Ivan Ilitch na repartição. Há algumas semanas estava enfermo e todos aguardavam a malfadada notícia. Das falas sobre a morte, Ivan emerge da maneira mais sórdida: "tinha fortuna?" é uma das perguntas que surgiam. Pesaram também sobre os colegas mais próximos os entediantes deveres junto ao funeral, sobretudo Pietro Ivanovitch, que fora colega do morto na Escola de Jurisprudência. Ao chegar ao velório, este se deparou com Schwartz, seu amigo de claros traços de expressão mundana, que lhe piscou um dos olhos em feição de ironia amarga e de desdém para a morte. Ambos estavam trocando olhares para combinarem quando poderiam se safar do velório para algumas partidas de whist. Os cerimoniais transcorreram arrastados como todos os cerimoniais de velórios. Todas as personagens, sobretudo as consideradas mais próximas do morto, têm de desempenhar os seus papéis, que tendem entre a dor da perda e a vontade de voltar à realidade da vida. A partir do segundo capítulo, valendo-se do recurso da figura da prolepse, a narrativa recua no tempo e passa a "contar a história" de vida de Ivan Ilitch. Sua história reproduz muitas e muitas vidas que conhecemos sem tirar nem acrescentar nada. E nisso é exemplar Tolstói, apresentando como se fosse uma vida original. Vida imitativa do pai e da tradição de empregos burocráticos da Rússia anterior à revolução. Filho do meio mais simpático, mais dócil, mais nada. Vivia se espelhando nas ações dos outros. Mediocridade existencial. Muito apreciado como bom funcionário. Dezessete anos de vida comum, depois do casamento. Apenas evolução de cargos e de esperas. Máximo da superficialidade mundana. O perfil de vida de Ivan Ilitch assim se apresenta na novela:

"Ivan Ilitch passava as manhãs no Palácio da Justiça e voltava a casa para almoçar. Durante a primeira época, costumava estar de bom humor, embora sua nova instalação o fizesse sofrer um pouco. Qualquer manchazinha numa toalha ou numa tapeçaria ou uma borla rota o irritava. Havia tomado tanto trabalho com o arranjo da casa que a menor imperfeição o magoava. Mas em geral, sua existência decorria de acordo com suas crenças; era fácil, agradável e correta".

Uma existência “fácil, agradável e correta" que nos reporta imediatamente ao humor irônico de Machado de Assis, aponta para a linearidade da vida tal como ocorre com os animais e as plantas. Trata-se de uma vida sem nenhum vislumbre existencial, sem nenhum recorte vertical que possa nos remeter a um aprendizado pela experiência. Por isso se justifica "qualquer manchazinha numa toalha ou numa tapeçaria ou uma borla rota" irritar a Ivan Ilitch. Não podemos afirmar que a inexorável morte seja agradável para quem quer que seja, mas podemos afirmar que, quanto mais o sujeito estiver "voltado para a vida", isto é, para as minudências da vida, sem agoras verticais, mais a verdade da morte, mais a sua urdidura severa, recairá de maneira avassaladora e cruel. Dentro desse panorama, Tolstói elege o gênero novela para comportar os passos da morte de um indivíduo que sai de sua condição "normal” de saúde para chegar à condição de cadáver. O fenômeno em si ocorre com todos nós, seres viventes. Entretanto, as escalas de sofrimento para essa travessia é que variam de um ser humano para o outro. Como se expressa Mario Quintana no poema "No Quarto": 
"Este quarto de enfermo, tão deserto de tudo, pois nem livros eu já leio e a própria vida eu a deixei no meio como um romance que ficasse aberto...

Que meimportaeste quarto,em que desperto como se despertasse em quarto alheio? Eu olho é o céu! Imensamente perto, o céu que me descansa como um seio.

Pois só o céu é que está perto, sim, tão perto e tão amigo que parece um grande olhar azul pousado em mim.

A morte deveria ser assim: um céu que pouco a pouco anoitecesse e a gente nem soubesse que era o fim...".

Quisera que a bela imagem do céu que anoitece para representar a morte fosse real. No filme $O$ Sétimo Selo, Bergman constrói, nesse sentido, alegorias fundamentais. Apesar de a Morte estar assolando a Suécia por meio da lepra, a relação das personagens com ela depende do grau de "profundidade de espírito" de cada um. Mas não devemos ver essa questão como se fora do cinema ou da literatura. Trata-se de uma questão das mais sérias de todos nós; trata-se de uma lição que o ser humano recebe e que insiste em não aprender.

Os índices da doença de Ivan Ilitch vão conduzi-lo à degenerescência física e moral, levando-o a total desespero. A visão extremamente superficial da vida, assegurada por certezas sobre pequenas coisas e toda presa a limites, restringiu demais as possibilidades de compreensão da própria vida e certeiramente da morte. Ivan (no fundo de sua alma) sabia que ia morrer, mas não se acostumava com essa ideia. Ele deu as costas para a morte a vida inteira. Paradoxalmente, dar as costas para a morte significa ficar apenas com metade da vida.É também não chegar a compreendero sentido da vida. A visão da personagem era maniqueísta. Ao tomar consciência de sua doença, e mais, da gravidade de sua doença, Ivan Ilitch acaba se envolvendo com o outro extremo: passa a viver em função da ideia de morte. Da forma extremamente linear de vida que vivia, marcada pela temporalidade cronológica, passa, como enfermo, a viver dias iguais definidos apenas pela intensidade da dor e do sofrimento. Ivan não consegue resgatar a noção de temporalidade. Ivan no Tribunal, tentando ser natural no trabalho,é traído pela presença da dor que o embate: "a dor começava sua obra roedora".Amorte se personifica e se impõe diante dele. Torna-se personagem dominadora que leva Ivan a perder o brilho dos olhos e a cometer erros diante dos amigos e colegas. Ivan buscava outros véus atrás dos quais tentava se esconder, mas a morte os atravessava em curto período de tempo. Buscava contrariedades que o distraíssem. "Deixe que os criados façam isso", lembrava-lhe a esposa. Mas a obsessão da presença da morte era como um martelo a ser desferido ininterruptamente.

Contrariando esse despreparo para a recepção da morte, o poema de Manuel Bandeira, epígrafe deste ensaio, traz os ingredientes básicos para o início de um tratamento do tema da morte. Antes, porém, nossos devidos respeitos à misteriosa e fascinante esfera da morte, e é exatamente por ser assim que humildemente tentaremos nos aproximar de seus torneios, com o tabuleiro e as peças na mão, incitando-a para o jogo.

Como o poema é um pensamento por imagens, nelas encontramos o que o discurso argumentativo não consegue explicitar. Como epígrafe, o poema simboliza o fio de prumo para a abordagem desse assunto tão precioso para todo ser humano. Na economia das palavras e no gesto da linguagem, a morte vai se apresentando a nós tangenciada por todos os elementos que a constituem. A primeira imagem do poema, o próprio título, consiste numa metáfora do restante e nos chama a atenção para o seu sentido. "Consoada", entendida como pequena ceia de natal realizada em família, resume o que é determinado em todo o poema: a noção do alimentar-se em situação especial, do alimentar-se em aconchego, em proteção. Já de início, portanto, o poema nos afasta da ideia negativa da morte em si. Não falamos, por enquanto, das mais variadas formas de morte, das mais variadas circunstâncias da morte. Falamos da morte em si, da chegada 


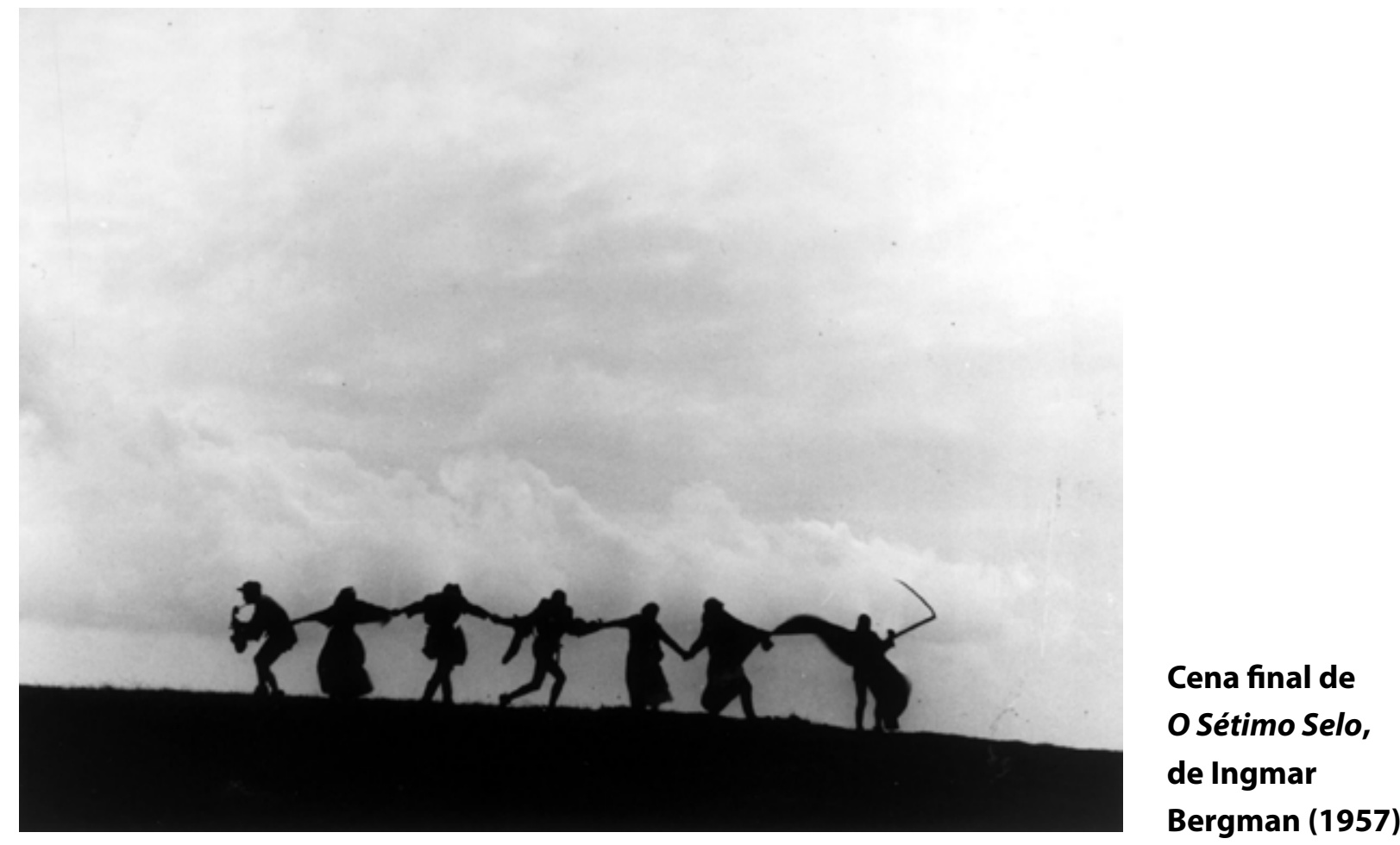

da morte descarnada. E o retrato da morte se estampa no rosto do poema. Sua fisionomia se mostra paradoxalmente serena. O recurso antropofágico é inevitável. Não se sabe, nessa ceia, quem é quem. Para procedimento tão natural da vida humana, a morte envolve um sem-número de aspectos que a tornam complexa. Portanto, a complexidade da morte não está nela, mas nos procedimentos de vida. A não ser por algum tipo de distúrbio que impulsiona o indivíduo para a morte, enquanto resta um fio de vida o ser humano quer viver. $\mathrm{E}$ essa é a noção maior que o filme $O$ Sétimo Selo constrói. Por mais que os pensadores demonstrem e denunciem a trágica condição de viver, por mais que antropólogos mostrem as condições sub-humanas de certos povos, prefere-se viver a morrer. A tensa relação de euforia/disforia no gesto de viver reside na manutenção do sistema caótico do ser humano e não no pairar da linearidade estável da condição da morte. Quando em momentos de desequilíbrio se blasfema e se evoca nervosamente a morte, sempre depois se acalma e se arrepende. Ninguém quer morrer. Morrer é estagnação e desfalecimento, e não temos certeza dos destinos de nossa alma e no que ela consiste. Isso evidentemente gera desconforto e medo mesmo para os que dizem se encontrar mais bem preparados para acolhê-la.

A chegada da morte é implacável. E é como se o processo de existência nos fizesse fingir que estamos sempre ocupados, sem tempo para atendê-la. Mas ela é paciente e imponderável. É uma emissária insistente e nada a demove de sua decisão ao chegar a hora. O “quando", primeira palavra do poema de Bandeira, nos conduz a essa inexorável condição de chegada, a esse pontual estado de interrupção da dinâmica do tempo, a essa condição factual e pontual dentro da linha da vida. E ela, a morte, é nomeada, com muita pertinência, de "Indesejada das gentes”. E é com ela, ou contra ela, que travamos todas as batalhas, em busca de um pouco mais de vida.

Voltemos ao filme $O$ Sétimo Selo, de 1957. Trata-se de uma das mais realistas e belas alegorizações da morte e seus veios dialéticos na tensa relação com a Vida. A propósito, para a abordagem com mais intensidade sobre o assunto, torna-se impossível isolar cada parte do binômio. Quão maior for o tom evasivo e superficial 
do mesmo, mais fácil se tornará analisar cada uma de suas partes. Ingmar Bergman possui a fina ressonância dos sentidos que se movimentam no mundo interior do ser humano e trabalha nos seus filmes esse ir e vir do evoluir vital e do desfalecer permanentes na luta do insondável marcado pelas dissensões existenciais. Em $O$ Sétimo Selo essas questões são acentuadas e reúnem várias das indagações que estão sendo tratadas neste texto. O filme consegue ser dramaticamente de aventura em que se trava um duelo com a Morte em que ela sempre vence. As unidades de sentido do filme apontam para uma isotopia: a agonia da espera da morte.

A fábula é de um cavaleiro medieval com seu escudeiro, voltando das Cruzadas e viajando por uma Europa devastada pela peste e pela crença religiosa transformada em medo. É fundamental que Bergman
Algumas cenas do filme de Bergman tenha mesclado os gêneros na composição do filme. $O$ cineasta consegue metaforizar de modo muito realista (eis um paradoxo) exatamente a condição humana de um

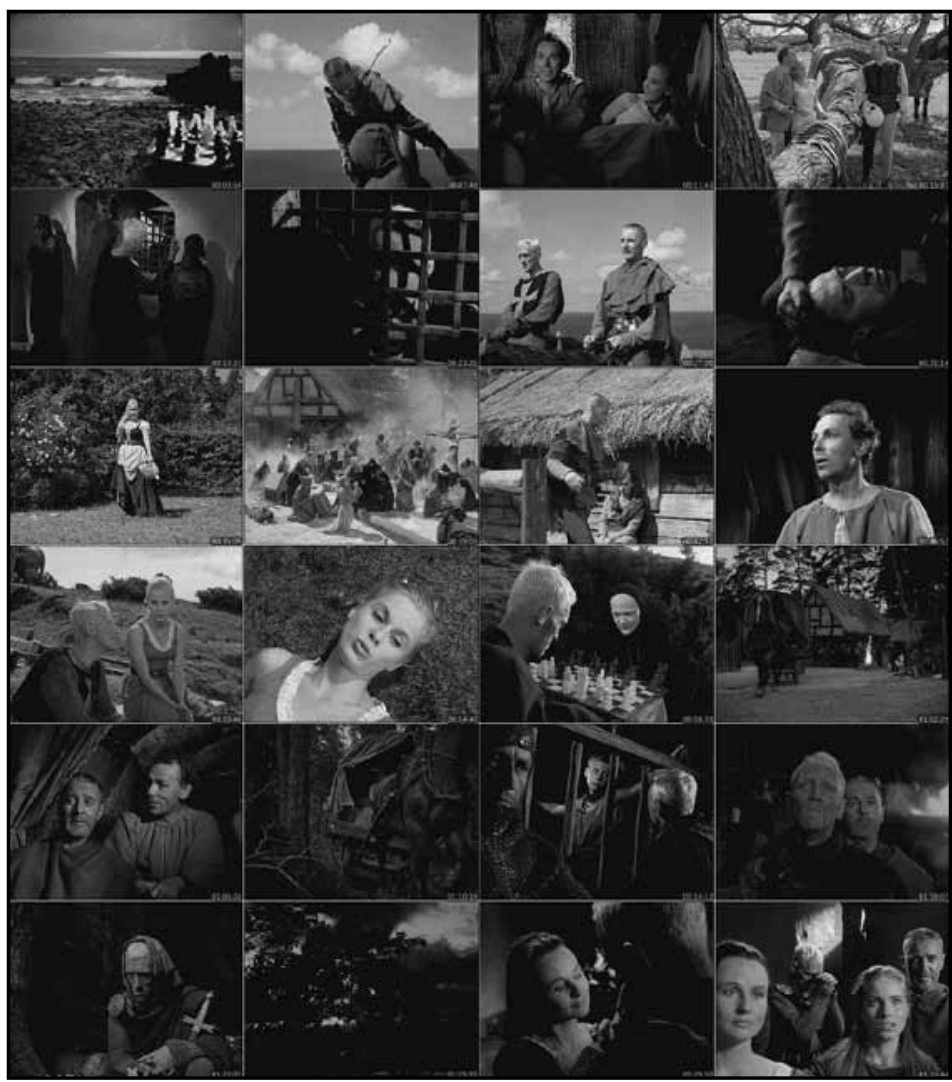

modo encantatório, como se dá com as pessoas que vivem se sentindo eternas. Nesse sentido, o filme consegue reunir a condição dramática da morte, por meio da epidemia da peste, e do medo iconizado pela religiosidade, a comédia, por meio de várias cenas de vida posta na condição do riso (traições amorosas e arrependimentos falsos); participação irônica do escudeiro que parece assistir jocosamente às cenas do cotidiano. Relações disjuntivas em aparentes conjunções de personagens, como é o caso do escudeiro que na verdade atua como contraponto do cavaleiro. Enquanto Block, o cavaleiro, busca respostas sobre o sentido da vida e de Deus, o escudeiro não apresenta nenhuma perspectiva existencial, mas é o que mais sente, mediante atitudes de horror manifestadas no filme.

Ingmar Bergman é o diretor mais famoso da Suécia com obras geniais realizadas que vale a pena ser vistas. Acabou consagrado como diretor (já era reconhecido como excelente roteirista) com o filme O Sétimo Selo, quando ganhou o prêmio especial do júri do Festival de Cannes de 1957. O realismo a que aludimos em Tolstói encontra em Bergman a sua parceria iluminada. Escolheu retratar o período de uma maneira mais árida, fotografando em preto e branco e percorrendo vastos campos vazios onde se encontram, perdidos nesse ambiente, algumas moradias castigadas por aquele período terrível, regado pela fome, doença, guerra e fervor religioso que amedrontavam a população, tomando conta de seus sentidos e da razão, criando um aspecto de loucura generalizada. Mais ainda sua originalidade se manifesta ao se valer de elementos medievais com técnicas renascentistas para o trabalho de montagem e de enquadramento. A escolha do sétimo selo, essa alusão ao Apocalipse, fundida às cenas da vida mundana no seu mais puro e genuíno aspecto; o trabalho com a condição humana naquele sentido tão bem apontado pelo teatro de Gil Vicente ou pela pintura de um Pieter Brughel, essa escolha confere ao filme seu realismo pelo avesso: o desatino da alma humana e a sua insana condição de ter de estar viva. Os 
agentes da guerra e destruição, doença e peste, fome e desespero, além da morte, sempre presente e criadora do paradoxo entre certeza e incerteza, integram-se no filme de modo a gerar em nós o estranho incômodo de delineio da vida com essa face tão crua. As escolhas do cineasta são poeticamente marcadas, fazendo-nos perceber a função de cada procedimento do código complexo que possui o cinema. Ao congelarmos as cenas do filme, todas elas nos reportam a verdadeiros quadros, verdadeiras pinturas, com feições teatrais ou plásticas, como se o tempo todo o diretor realizasse tomadas significativas construindo tomadas que fundissem o belo e o dramático como ocorre com a própria condição do ser humano mediante o fenômeno mors-amors. Bergman se vale de procedimentos de outras artes próprias do Renascimento para criar a mais crua realidade que consegue produzir o cinema. Utiliza-se de técnicas renascentistas que centralizam cenas no centro da tela, com estruturas geométricas voltadas para a triangulação, para a feição religiosa e coletiva da morte.

Mas isso que no filme é alegorizado de forma intencional e explícita é cuidadosamente soterrado na novela de Tolstói, que também se valeu da morte gradativa de um homem para que fosse possível discutir sobre a existência e os desígnios de nossa vida. Chamo a atenção ao belo plano em que se sentam, frente a frente, de perfil para o espectador, o cavaleiro a Morte, iniciando a disputa estratégica, tendo no centro o tabuleiro com as peças pretas e brancas, e no fundo aquele céu tenebroso e escuro. $\mathrm{O}$ lúdico parece intermediar simbolicamente as tensas relações do Homem com a Morte. Na novela temos sua marca pelo jogo de cartas - o whist - e no filme temos o jogo de xadrez. A partir do momento em que Antonius encontra-se face a face com a Morte, iniciam-se nele questionamentos a respeito de sua própria existência e sobre o sentido das religiões e, em resumo, sobre Deus. Trata-se de um misto de ceticismo e de querer ter crença pela esperança do que há por vir pela Morte. O temor da morte e as incertezas causadas pela sua presença estão atuantes durante todo o filme, seja em Antonius, seja no saltimbanco que acaba morrendona floresta de maneira curiosa, ou na população que está encarando a Peste, sendo acusada pelos sacerdotes de ser a culpada por sua sina, graças à sua descrença e mundanismo.

Os questionamentos religiosos e existencialistas estão sempre presentes. O cavaleiro está perturbado com a possibilidade de morrer, chegando ao ponto de considerar que aquele vazio que sente dentro de si é causado pela falta de significado da própria vida e sua religiosidade. Antonius considera que sua vida fora em vão mas espera, com esse tempo que conquistara ao desafiar a Morte, adquirir a maior quantidade de conhecimento possível, desejo expresso também na lenda do Fausto, que vende a alma ao Diabo em troca dessa realização - a coincidência entre o caso dessas duas personagens é algo que merece certa reflexão. O Cristo que aparece alternadamente aos planos feitos do cavaleiro nos dá a ideia da menção de uma plena discussão sobre o real estado de espírito de Jesus quando descobriu que seu sacrifício era eminente. Será que absorvera sereno, ou discutiu sua sanidade, destino e o futuro que lhe era desenhado e que estaria sendo usurpado por seus juízes? O que se deve assinalar no filme de Bergman é que os verdadeiros juízes são aqueles que extraviam ou tentam extraviar a Morte de seus desígnios naturais.

Antes, porém, é fundamental que se examine o valor semântico do vocábulo "natural". Do latim naturale: da, ou referente à natureza; produzido pela natureza; em que não há trabalho ou intervenção do homem; que segue a ordem regular das coisas; espontâneo, etc. Partindo desses princípios semânticos, torna-se completamente impossível falar da "naturalidade da morte" sem falar da "naturalidade da vida". $\mathrm{O}$ ato de conferir vida implica o ato de se conferir morte.

A abordagem desse item implica uma relação de tensões entre dois eixos semânticos que se opõem e se implicam: a dimensão eufórica dos sentidos e sua 
dimensão disfórica. Convivemos com essas duas categorias desde que nascemos $\mathrm{e}$, ironicamente, quem anuncia a vitalidade do nascer (euforia) é a expressão do choro (disforia). E o corpo que se põe ao mundo é completo e complexo - um universo de múltiplas relações interligadas.

Como já dissemos, O Sétimo Selo de Ingmar Bergman consiste numa exemplar alegoria sobre a morte. $O$ fato de se tratar de linguagem fílmica, em que o senso de realidade é tão intenso, faz o diretor sueco realizar verdadeira "trança" dialética entre os componentes da tessitura da morte que na verdade recupera o sentido manifestado pela concepção latina, presente na poesia de Horácio em mors-amors, e cria um uníssono na concepção de vitae. O filme é realizado na dimensão que o tema exige e não perde em nenhum momento os parâmetros de seu significado, tentando resolver a enigmática condição de morrer.

O que mais nos atrai nessa aproximação entre a novela de Tolstói e o filme de Bergman é o movimento dialético entre a solidão do sujeito diante da morte e a visão coletiva da mesma questão. Na novela, o movimento se dá de umailusória condição de felicidade social, que vai se enfraquecendo mediante a aproximação da doença, para a tomada de consciência de sua morte.

\section{- $\bullet$}

Para finalizar, gostaria de sugerir ao leitor aficionado pelo tema da morte algumas obras fílmicas que julgo do maior interesse. Venho trabalhando com elas, para buscar alguns fundamentos de Tanatologia, como parte de nossos estudos na Famerp. Assinalo, portanto, três filmes que têm se tornado alvos de nossas perquirições, cada um elegendo um recorte da maior relevância para a tentativa de aproximação desse tema tão complexo que é a morte. São eles, O Quarto do Filho, do diretor italiano Nanni Moretti, o filme Wit, dirigido por Michel Nichols e estrelado por Emma Thompson, e ainda o filme japonês A Partida, de Tojiro Takita. Interessante que as abordagens conferidas aos filmes reúnem todos os ingredientes que vimos discutindo até aqui, a partir das obras escolhidas. Sintetizando o máximo possível as três linhas isotópicas respectivas, temos primeiramente, no filme italiano, a questão das quatro fases do luto mediante a morte de um ente querido: a quase presença, a ausência, a perda e a falta, e como os problemas pessoais de cada personagem vão refletir no modo de conviver com essas fases. No filme protagonizado por Emma Thompson temos a dramática condição de Vivian Bearing, professora doutora, especialista em poesia metafísica do século de John Donne, nos seus oito meses finais de vida, tratando de um câncer no ovário. Nesse caso, temos a paulatina tomada de consciência pelo sofrimento da racionalíssima paciente, diante da morte que se aproxima.

O filme apresenta dois caminhos ou duas formas de visão do homem que poderão definir suas condições diante da existência e, consequentemente, diante da questão da morte: a primeira delas mostra a vida no seu sentido natural, com procedimentos explicáveis, marcados pela racionalidade e pelos procedimentos cognitivos. Nesse sentido, a ideia de tratar, cuidar ou curar o humano se assemelha a qualquer outra forma de objeto. No filme se assemelham o câncer em quarta etapa de evolução e o poema metafísico com seus jogos paradoxais. A segunda condição envolve a vida em sua condição não apenas natural mas num sentido mais profundo em termos de vivência, onde comportam os sentimentos de amor e de humanidade.

Já no filme japonês A Partida, de Tojiro Takita, a personagem Daigo Kobayashi, ex-violoncelista de uma grande orquestra, torna-se por necessidade de emprego um nokanshi, mestre em lavar e vestir cadáveres. Essa função advém de uma antiga tradição japonesa de deixar o morto limpo, beloe bem tratado para seu último momento, função antes exercida pelas famílias dos mortos, mas já meio esquecida e agora por conta de profissionais. Completamente assustado no início, Daigo passa a se entregarà profissão e dela passa a extrair o verdadeiro sentido da própria vida. 